\title{
Evaluation of HIV protease and nucleoside reverse transcriptase inhibitors on proliferation, necrosis, apoptosis in intestinal epithelial cells and electrolyte and water transport and epithelial barrier function in mice
}

Manuel B Braga Neto', Carolina V Aguiarr', Jamilly G Maciel', Bruna MC Oliveira', Jesus E Sevilleja², Reinaldo B Oriá1 ${ }^{1,2,3}$, Gerly AC Brito ${ }^{3,4}$, Cirle A Warren², Richard L Guerrant ${ }^{1,2^{*}}$, Aldo AM Lima ${ }^{1,2,4}$

\begin{abstract}
Background: Protease inhibitors (PI's) and reverse transcriptase drugs are important components of highly active antiretroviral therapy (HAART) for treating human acquired immunodeficiency syndrome (AIDS). Long-term clinical therapeutic efficacy and treatment compliance of these agents have been limited by undesirable side-effects, such as diarrhea. This study aims to investigate the effects of selected antiretroviral agents on intestinal histopathology and function in vivo and on cell proliferation and death in vitro.
\end{abstract}

Methods: Selected antiretroviral drugs were given orally over 7 days, to Swiss mice, as follows: $100 \mathrm{mg} / \mathrm{kg}$ of nelfinavir (NFV), indinavir (IDV), didanosine (DDI) or $50 \mathrm{mg} / \mathrm{kg}$ of zidovudine (AZT). Intestinal permeability measured by lactulose and mannitol assays; net water and electrolyte transport, in perfused intestinal segments; and small intestinal morphology and cell apoptosis were assessed in treated and control mice. In vitro cell proliferation was evaluated using the WST-1 reagent and apoptosis and necrosis by flow cytometry analysis.

Results: NFV, IDV, AZT and DDI caused significant reductions in duodenal and in jejunal villus length ( $p<0.05$ ). IDV and AZT increased crypt depth in the duodenum and AZT increased crypt depth in the jejunum. NFV, AZT and DDI significantly decreased ileal crypt depth. All selected antiretroviral drugs significantly increased net water secretion and electrolyte secretion, except for DDI, which did not alter water or chloride secretion. Additionally, only NFV significantly increased mannitol and lactulose absorption. NFV and IDV caused a significant reduction in cell proliferation in vitro at both $24 \mathrm{~h}$ and $48 \mathrm{~h}$. DDI and AZT did not alter cell proliferation. There was a significant increase in apoptosis rates in IEC-6 cells after $24 \mathrm{~h}$ with $70 \mathrm{ug} / \mathrm{mL}$ of NFV (control: $4.7 \%$ vs NFV: 22\%) while IDV, AZT and DDI did not show any significant changes in apoptosis compared to the control group. In jejunal sections, IDV and NFV significantly increased the number of TUNEL positive cells.

Conclusion: The PI's, NFV and IDV, increased cell apoptosis in vivo, water and electrolyte secretion and intestinal permeability and decreased villus length and cell proliferation. NFV was the only drug tested that increased cell apoptosis in vitro. The nucleoside reverse transcriptase inhibitors, AZT and DDI, did not affect cell apoptosis or proliferation. These findings may partly explain the intestinal side-effects associated with PI's.

\footnotetext{
* Correspondence: rlg9a@virginia.edu

'Institute of Biomedicine and Clinical Research Unit-University Hospital,

Federal University of Ceará, Fortaleza, Brazil

Full list of author information is available at the end of the article
} 


\section{Background}

Protease inhibitors (PI's) and reverse transcriptase drugs (RTs) are important components of highly active antiretroviral therapy (HAART) for treating human acquired immunodeficiency syndrome (AIDS) and have significantly changed the natural history of AIDS, increasing life expectancy and quality of life [1,2]. These drugs are known to reduce human immunodeficiency virus (HIV) load and increase circulating CD4 T cells, thus resulting in fewer gastrointestinal conditions, ultimately reducing hospitalization, and enhancing life expectancy in HIVinfected individuals $[3,4]$. However, long-term clinical therapeutic efficacy and treatment compliance of these agents have been limited by undesirable side-effects, such as diarrhea, most commonly seen with ritonavirboosted PI's, and enteric infections, which have been reported to occur in up to $62 \%$ of patients [4-6].

Although life-saving benefits of HAART are wellknown, antiretroviral intestinal side-effects have not been explored in animal models and the mechanisms of HAART-induced intestinal epithelial damage in vitro are still poorly understood. There is a scarcity of in vivo and in vitro studies that evaluate the effects of these agents on intestinal barrier function. Bode et al, 2005, reported decreased transepithelial resistance in HT-29 monolayers after treatment with PI's, accompanied by massive cell apoptosis but not necrosis [7]. Since these initial findings, several studies have been conducted both in vitro and in vivo, suggesting the potential benefits of HIV PI's in chemotherapy [8]. Nelfinavir has been demonstrated to induce endoplasmic reticulum (ER) stress, autophagy and apoptosis both in vivo and in vitro and the authors have, therefore, suggested it could be repositioned as a chemotherapy agent [9]. Another study demonstrated that PI's induce secretory diarrhea, by potentiating muscarinic chloride secretion in T 84 cells through amplification and prolongation of an apical membrane $\mathrm{Ca}^{2+}$-dependent chloride conductance [10].

Our group has demonstrated that intestinal epithelial barrier breakdown due to enteric infections and diarrhea might lead to antiretroviral drug malabsorption and increased drug resistance [11]. Improvements of gastrointestinal symptoms and antiretroviral drug levels were found with oral glutamine derivatives in a randomized clinical trial enrolling hospitalized AIDS patients after seven days of intervention [12]. However, it is of great importance to further understand the mechanisms involved in this process in order to optimize possible future interventions that can lead to a decrease in side effects such as diarrhea.

The intestinal epithelial barrier is composed of an extremely dynamic cell population, which behaves differently during intestinal adaptation following mucosal injury [13]. This epithelial lining is renewed with a highly active cell turn over by means of their surrounding crypts, from where stem cells migrate and differentiate towards the villus tip [14-17]. This current study assessed changes in the intestinal barrier function from selected anti-retroviral drugs in mice and in intestinal epithelial cells, thus shedding light on specific drug-host interactions and intestinal side effects of targeted antiretroviral therapy.

\section{Methods}

\section{Reagents and drugs}

Mellibiose and chemicals for enteric perfusion, including $\mathrm{NaCl}, \mathrm{KCl}, \mathrm{CaCl}_{2}, \mathrm{NaHCO}_{3}$, and $\mathrm{NaH}_{2} \mathrm{PO}_{4}$, and sodium citrate were obtained from Sigma-Aldrich, St. Louis, MO. Lactulose and mannitol were purchased from Luitpold Produtos Farmacêuticos Ltda., Barueri, SP, and from Henrifarma Produtos Químicos e Farmacêuticos, São Paulo, SP, Brazil, respectively. Nelfinavir (NFV), indinavir (IDV), zidovudine (AZT), and didanosine (DDI) were kindly granted by the Infectious Diseases' State Hospital São José, Fortaleza, CE, Brazil, solely for the purpose of rodent experiments. Tetrazolium salt WST-1 reagent was obtained from Roche (Mannheim, Germany). Mitomycin $\mathrm{C}$ was obtained from Roche (Mannheim, Germany). Annexin V Apoalert kit with Binding buffer was obtained from BD Biosciences (Clonetech, Palo Alto, CA). ApopTag Plus Peroxidase In Situ Detection Kit (Serologicals Corp., Norcross, GA). AZT, DDI, IDV and NFV used for cell culture compounds were obtained through the AIDS Research and Reference Reagent Program, Division of AIDS, NIAID, $\mathrm{NIH}$.

\section{Animals}

Male Swiss mice weighing 30 to $40 \mathrm{~g}$ were obtained from the Clinical Research Unit \& Institute of Biomedicine animal facility (Federal University of Ceara), and were housed in temperature-controlled rooms prior to animal experiments. All animals received standard mice chow diet and water ad libitum. Surgical procedures, animal handling and treatment were reviewed and approved by the Animal Care and Use Committee at the Federal University of Ceara, according to the Brazilian College for Animal Experimentation guidelines (COBEA).

\section{Treatment regimen}

Animals were weighed and randomized into different treatment groups. NFV, IDV, AZT, and DDI were diluted in sterile phosphate buffer (PBS), as vehicle, and a control group treated only with PBS. Each group consisted of six or more animals. NFV $(100 \mathrm{mg} / \mathrm{kg})$, IDV 
(100 mg/kg), AZT (50 mg/kg) and DDI (100 mg/kg) or PBS, were given orally by gavage on days 1 through 7 . In order to find an evaluable regimen for testing, we conducted a pilot study to evaluate survival rates using the following concentrations: NFV (100 and $300 \mathrm{mg} / \mathrm{kg}$ ); IDV (300 mg/kg); AZT (100 and $300 \mathrm{mg} / \mathrm{kg}$ ) and DDI (150 and $100 \mathrm{mg} / \mathrm{kg}$ ). Doses and the experimental course (one week-treatment) were defined based on the survival data. All animals were weighed and clinically examined daily for diarrhea until the study end point. Data on nutritional intake was not collected during the time of the experiment. Therefore, we cannot exclude differences in nutritional intake between the groups.

\section{Histology and Intestinal Morphometry}

Mice were sacrificed by a lethal injection of a euthanasia solution containing chloral hydrate $(250 \mathrm{mg} / \mathrm{kg}$, i.p), under anesthesia, on day 8 . Immediately after euthanasia, $0.5 \mathrm{~cm}$-samples were harvested from different intestinal segments, as follows: duodenum, jejunum, and ileum, based on anatomical hallmarks. Tissue specimens were fixed in $10 \%$ neutral buffered formalin, and dehydrated for $12 \mathrm{~h}$. On the following day, specimens were cut with a razor blade and then stored in $70 \%$ ethanol for paraffin embedding. 5 um-thick cross-sections were prepared for hematoxylin-eosin staining (HE). Crypt depth and villus height were measured from HE stained slides on a light microscope equipped with a digital camera, and a computer-aided image capture system. Villus height was measured from the tip to the villuscrypt junction. The crypt depth was measured from the villus-crypt junction to the crypt bottom. At least 10 clear longitudinal sections of the villi and the crypts were selected randomly from each sample, measured with an eyepiece ruler and averaged after proper calibration. All morphometric analyses were conducted blindly regarding experimental groups and diarrheal outcomes. Morphologic analyses were carried out by only one investigator in a blinded manner; hence inter or intraindividual variability was not assessed.

\section{In vivo Analysis for Cell Death}

Analysis of apoptosis or necrosis was performed using ApopTag Plus Peroxidase In Situ Detection Kit (Serologicals Corp., Norcross, GA) for TUNEL (terminal deoxynucleotidyltransferase-mediated dUTP-biotin nick end labeling). The ApopTag Plus Peroxidase. In Situ Detection Kit distinguishes apoptosis from necrosis by specifically detecting DNA cleavage and chromatin condensation associated with apoptosis. However, there may be some instances where cells exhibiting necrotic morphology my stain lightly or in rare instance, DNA fragmentation can be absent or incomplete in induced apoptosis. Thus, the results were presented as TUNEL positive cells as recommended [18]. Pariffin-embedded intestinal tissue samples sections were hydrated and incubated with $20 \mu \mathrm{g} / \mathrm{ml}$ of proteinase K (Sigma, New York) for 15 minutes at room temperature (RT). Endogenous peroxidase was blocked by treatment with $3 \%$ (wt/vol) hydrogen peroxide in PBS for 5 minutes at RT. Slides were then washed with PBS and sections were incubated in a humidified chamber at $37^{\circ} \mathrm{C}$ for $1 \mathrm{~h}$ with TdT buffer containing TdT enzyme and reaction buffer. Afterwards, samples were incubated for $10 \mathrm{~min}$ at RT with a stop/wash buffer and then incubated in a humidified chamber for $30 \mathrm{~min}$ with anti-digoxigenin-peroxidase conjugate at RT. Samples were then washed several times in PBS, the slides were covered with peroxidase substrate to develop color and then wash in three changes of distilled $\mathrm{H}_{2} \mathrm{O}$ and counterstained in $0.5 \%$ (vol/vol) methyl green for 10 minutes at RT. Cell apoptosis was measured by counting under a light microscope the number TUNEL positive cells, which represent apoptotic cells and possibly some necrotic cells. At least 10 randomly selected sections from each sample were counted and averaged.

\section{Intestinal Absorption and Permeability}

The lactulose/mannitol ratio (L:M) was used in this study as the primary parameter to evaluate the integrity of the intestinal barrier function. Mannitol, a monosaccharide, is considered a biological marker of total intestinal absorptive area, since it is absorbed transcellularly. In contrast, lactulose, a disaccharide, is a marker of mucosal damage, since it is only absorbed paracellularly. Animals were fed with a low carbohydrate-chow diet on days 5, 6 and 7 of the treatment regimen. On day 7 , mice were fasted overnight $(8-12 \mathrm{~h}$ ) and placed in metabolic cages (3 animals/cage). On day $8,0.25 \mathrm{ml}$ of a solution containing lactulose $(20 \mathrm{mg} / \mathrm{mL})$ and mannitol $(50 \mathrm{mg} / \mathrm{mL})$ was given to the experimental mice by gavage. After $1 \mathrm{~h}$ the animals regained access to food and water ad libitum. The urine was collected during the next 24 hours in a flask and mixed with a $25 \mathrm{uL}$-solution containing chlorhexidine $(40 \mathrm{mg} / \mathrm{mL})$. Total urine volumes were collected, aliquoted to $50 \mu \mathrm{l}$ and stored at $-20^{\circ} \mathrm{C}$ for further analyses. Each urine sample $(50 u \mathrm{l})$ was mixed with $50 \mathrm{uL}$ of a solution containing mellibiose $(3.6 \mathrm{mM})$ and diluted in $2.9 \mathrm{ml}$ of doubled-distilled and deionized water. After centrifugation and filtration via a Millipore membrane $(0.22 u \mathrm{~m})$, a $50 \mathrm{uL}$-filtered urine solution was employed for sugar determination using high-performance liquid chromatography (HPLC) with pulsed amperometric detection, as previously described [19]. Urinary recovery of both lactulose and mannitol was calculated as a percentage of the dose ingested. 


\section{Intestinal Net Fluid and Electrolyte Transport}

On day 7, experimental mice treated either with NFV, IDV, AZT, DDI or PBS, were fasted for $12 \mathrm{~h}$, with free access to water ad libitum. Animals were submitted to intestinal perfusion to evaluate net fluid and electrolyte transport. After ketamine $(35 \mathrm{mg} / \mathrm{kg}$, i.m.) and xylazine ( $5 \mathrm{mg} / \mathrm{kg}$, i.m.) anesthesia, a median 3- to 5-cm laparotomy was performed for visualization of the small intestine. An approximately $15-\mathrm{cm}$ ileal segment was selected and washed with $1 \mathrm{ml}$ of phosphate-buffered saline $(\mathrm{pH}$ 7.4), and the proximal and distal ends were ligated by means of polyvinyl cannulas for tissue perfusion. Polyvinyl cannulas (internal diameter $0.08 \mathrm{~cm}$.; outer diameter $0.26 \mathrm{~cm}$; Cole-Parmer Instrument Company, Vernon Hills, IL) were inserted approximately $5 \mathrm{~cm}$ distal to the ligament of Treitz and $5 \mathrm{~cm}$ proximal to the ileocecal valve (internal diameter, 0.085 in.; outer diameter 0.128 in.; Becton Dickinson, Sparks, MD). Ringer's solutions were pre-warmed to $37^{\circ} \mathrm{C}$, maintained at $\mathrm{pH} 7.4$, and introduced through the proximal cannula with the aid of a motorized pump (Masterflex C/L Pump System, Model 77120-62; Cole-Parmer Instrument Co.). Perfusion was maintained at the slow rate of $0.16 \mathrm{ml} / \mathrm{min}$ throughout the experiment. Samples were taken every 15 min throughout the 75-min study period for electrolyte and osmolarity measurements, as well as for determination of phenolsulfonphthalein (PSP) concentration. At the end of the perfusion, the animals were sacrificed, and the dry weight (after desiccation at $90^{\circ} \mathrm{C}$ for $72 \mathrm{~h}$ ) of the intestinal segment was used to calculate the perfusate flow and net water and electrolyte transport.

\section{Biochemical Analyses}

PSP $(50 u \mathrm{~g} / \mathrm{ml})$ was used as a non-absorbable marker for sodium, potassium, chloride and water net flux calculation. PSP was measured spectrophotometrically (Spectrophotometer Model C382; Microsonal S.A, São Paulo, SP, Brazil) according to the method developed by Schedl and Clifton [20]. Sodium and potassium concentrations in the perfusate were measured by flame photometry (Flame Photometer Model 443; Instrumentation Laboratory, Lexington, MA). The colorimetric method for chloride detection (Labtest Bio. Diagnostics, Belo Horizonte, MG, Brazil) was used according to the manufacturer's instructions. The osmolarity of the perfusion samples was measured with a vapor pressure osmometer (Model 5100C; Wescor, Logan, UT).

\section{Cell culture}

Rat intestinal jejunal crypt cells (IEC-6, passages 8-14) were purchased from American Type Culture Collection (Rockville, MD) and were cultured at $37^{\circ} \mathrm{C}$ in a $5 \% \mathrm{CO} 2$ incubator. The maintenance cell media was Dulbecco's Modified Eagle Media (DMEM; Gibco BRL, Grand
Island, NY) supplemented with 5\% Fetal Bovine Serum (FBS), $5 \mathrm{mg}$ bovine insulin, $50 \mathrm{ug} / \mathrm{ml}$ of penicillin/streptomycin (DMEM; Gibco BRL, Grand Island, NY) and a final concentration of $1 \mathrm{mM}$ of sodium pyruvate. The media was changed thrice a week, according to standard culture protocols. The cultured cells were trypsinized with $0.05 \%$ EDTA trypsin when $90-95 \%$ confluence was achieved.

\section{Cell proliferation}

Cell proliferation was measured indirectly using the tetrazolium salt WST-1 (4-[3-(4-iodophenyl)-2H-5-tetrazolio]1-3-benzene disulfonate), according to the manufacturer recommendations. A 96-well plate was seeded with IEC-6 cells in a total concentration of $4 \times 10^{3}$ cells/well in $100 \mathrm{uL}$ of DMEM media. Cells were allowed to attach for 48 hours, when the wells were washed with $100 \mathrm{uL}$ of DMEM media. The cells were then incubated for 24 and $48 \mathrm{~h}$ with either DMEM media or DMEM media incubated with NFV $(7 \mathrm{ug} / \mathrm{mL}, 10 \mathrm{ug} / \mathrm{mL}, 70 \mathrm{ug} / \mathrm{mL}$ and $100 \mathrm{ug} / \mathrm{mL}$ ), DDI $(5 \mathrm{ug} / \mathrm{mL}, 10 \mathrm{ug} / \mathrm{mL}, 50 \mathrm{ug} / \mathrm{mL}$ and $100 \mathrm{ug} / \mathrm{mL}$ ), IDV $(5 \mathrm{ug} / \mathrm{mL}, 10 \mathrm{ug} / \mathrm{mL}, 50 \mathrm{ug} / \mathrm{mL}$ and $100 \mathrm{ug} / \mathrm{mL}$ ) and AZT ( $5 \mathrm{ug} / \mathrm{mL}, 10 \mathrm{ug} / \mathrm{mL}, 50 \mathrm{ug} / \mathrm{ml}$ and $100 \mathrm{ug} / \mathrm{mL}$ ). After 24 and 48 hours, wells were incubated for 4 hours with $10 \mathrm{uL}$ of the tetrazolium salt and the absorbance was measured using an ELISA microplate reader at $450 \mathrm{~nm}$ (reference range $420-480 \mathrm{~nm}$ ). Tetrazolium salts are cleaved to formazan by mitochondrial enzymes in viable cells. Enhancement of the number of viable cells will result in an increase of the amount of the formazan dye, which is detectable by the ELISA reader. Therefore, this model indirectly measures cell proliferation in a time-dependent-manner. The experiments were carried out separately with individual control groups for each experiment, using different cell passages. Therefore, the analyses were done comparing values within each individual experiment.

\section{Flow Cytometry for Apoptosis and Necrosis}

Apoptosis and necrosis were measured by flow cytometry analyses using the ApoAlert annexin V kit. Annexin $\mathrm{V}$ is a molecule that binds to phosphatidylserine (PS) and when conjugated to a fluorochrome detects apoptotic cells expressing PS on the reversed membrane surface. For this protocol, propidium iodide was also used to detect necrotic and late apoptotic cells, which express propidium iodide inside the membrane. The cells were seeded on 12-well plates in a concentration of $5 \times$ $10^{5}$ cells/well. These cells were allowed to attach on the plate surface for 24 hours. Afterwards, cells were washed with DMEM media and incubated with NFV $(70 \mathrm{u} / \mathrm{mL})$, IDV $(100 \mathrm{ug} / \mathrm{mL})$, DDI $(100 \mathrm{ug} / \mathrm{mL})$, AZT $(100 \mathrm{ug} / \mathrm{mL})$. After $24 \mathrm{~h}$ of incubation, cells were trypsinized, centrifuged, and washed with serum-containing media, before 
incubation with annexin V. Cells were counted and diluted to $10^{5}-10^{6}$ cells and rinsed with $1 \times$ Binding Buffer, and re-suspended in $200 \mathrm{uL}$ of Binding Buffer. $5 \mathrm{uL}$ of annexin $\mathrm{V}$ and $10 \mathrm{uL}$ of propidium iodide were added and incubated for 5-15 min in the dark. The samples were then processed at the University of Virginia's Flow Cytometry Core, using a FACS Calibur dual laser (Becton Dickinson).

\section{Statistical Analyses}

Results are expressed as mean \pm standard error (SEM), as generated by GraphPad Prism version 4.0 (GraphPad software, San Diego, CA). The differences between the experimental groups were compared by one-way ANOVA, corrected by Bonferroni's multiple comparison tests.

\section{Results}

1) In vivo experiments

Survival rate and body weight

In order to define possible antiretroviral toxicity in our murine model, we have tested preliminarily different concentrations of antiretroviral drugs for 5 consecutive days. The tested concentrations are as follows: NFV (100 and $300 \mathrm{mg} / \mathrm{kg}) ;$ IDV (300 mg/kg); AZT (100 and $300 \mathrm{mg} / \mathrm{kg})$ and DDI $(150$ and $100 \mathrm{mg} / \mathrm{kg})$. The only group that presented significant toxicity was AZT, featured by mucous diarrhea, wasting, and death at the dose of $100 \mathrm{mg} / \mathrm{kg}(2 / 8=25 \%)$ and $300 \mathrm{mg} / \mathrm{kg}(4 / 8=$ $50 \%)$. Therefore, we decided to decrease AZT concentration to $50 \mathrm{mg} / \mathrm{kg}$. The minimum effective and safe dose of the antiretroviral agents was chosen for the remainder of the study. In order to assure a longer period of treatment, we increased the duration of antiretroviral therapy to seven days. All animals (at least $n=6$ per group) survived throughout the experimental course. NFV and IDV groups showed significant weight reductions as early as five treatment days. Seven days following treatment all antiretroviral groups showed significant weight decrements as compared to the untreated PBS control ( $\mathrm{p}<0.001)$, as seen in Figure 1.

\section{Effect of Antiretrovirals on Intestinal Villi Length, Crypt}

\section{Depth and Cell Apoptosis}

As shown in Figure 2A, antiretroviral drugs strikingly blunted duodenal villus height at day 8 , as compared to the unchallenged group treated with PBS $(\mathrm{p}<0.001)$. Proximal and mid-segments of the small intestine were most affected. IDV was the only drug tested that caused a significant decrease in ileal villus height. IDV significantly reduced villus height throughout the small intestinal segments, having a significant blunting effect in both the duodenum and ileum $(\mathrm{p}<0.05)$. As seen in Figure $2 \mathrm{~B}$, this morphological villus atrophy due to IDV was accompanied by increased crypt depth in the duodenum, and decreased crypt depth in the ileum. Most of

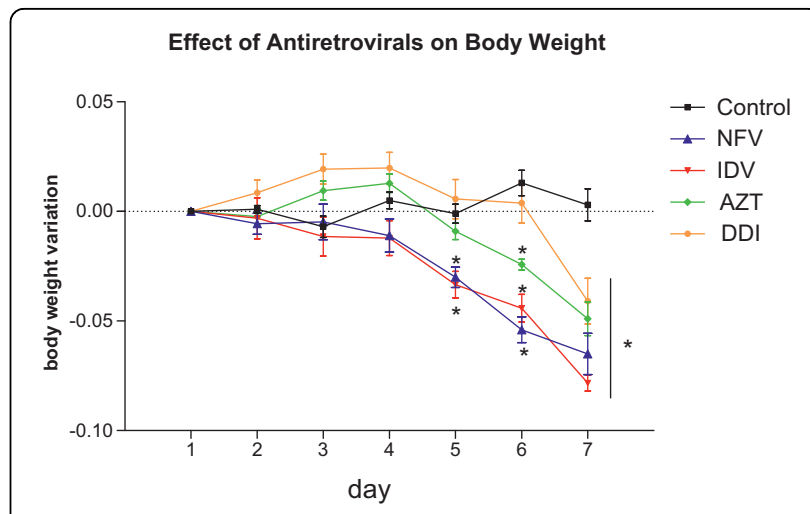

Figure 1 Effect of NFV (100 mg/kg), IDV (100 mg/kg), AZT (50 $\mathrm{mg} / \mathrm{kg}$ ) and DDI (100 $\mathrm{mg} / \mathrm{kg})$ on body weight in mice. Each animal was weighed daily throughout the experiment. The results are expressed as mean \pm SEM of at least six mice per group. ${ }^{*}$ statistical significance $(P<0.05)$ compared to the PBS control group by ANOVA, Bonferroni's multiple test.

the antiretroviral drugs tested (NFV, IDV and DDI) decreased the crypt depth in the ileal mucosa. A similar trend was seen with AZT, albeit not reaching statistical significance. Interestingly, only AZT induced crypt hyperplasia in both the duodenum and jejunum, in contrast to the other antiretroviral drugs, except IDV which only caused crypt hyperplasia in the duodenum. Figure $2 \mathrm{C}$ illustrates the effects of both protease inhibitors and reverse transcriptase on the intestinal villous length and crypt depth.

Both NFV and IDV increased the number of TUNEL positive cells (apoptosis and possibly necrosis) significantly by $89.6 \%$ and $180 \%$ compared to controls (cell death is indicated by the brown staining of the cells detected by the TUNEL method; Figure 3). AZT and DDI did not cause a significant increase in the number of TUNEL positive cells.

\section{Intestinal Electrolyte and Water Absorption}

NFV treatment caused significant increases in sodium (167\%), chloride (118.7\%), and water (260\%) secretion when compared to controls. Likewise, IDV caused significant increases, in sodium (97.5\%), chloride (36.5\%) and water (95.7\%) secretion. Treatment with AZT also increased sodium (102.9\%), chloride (36.6\%) and water (117.4\%) secretion. Treatment with DDI increased only sodium secretion (47.67\%). (Figure 4)

\section{Intestinal Absorption and Permeability}

NFV treatment increased lactulose and mannitol excretion significantly $(\mathrm{p}<0.05)$. Lactulose excretion increased from $1.32 \pm 0.24 \%$ to $3.94 \pm 0.68 \%$. However, mannitol excretion was also significantly increased from $3.014 \pm 0.6 \%$ to $6.41 \pm 1,08 \%$ after NFV chronic administration; hence there was no difference in the $\mathrm{L} / \mathrm{M}$ 
A

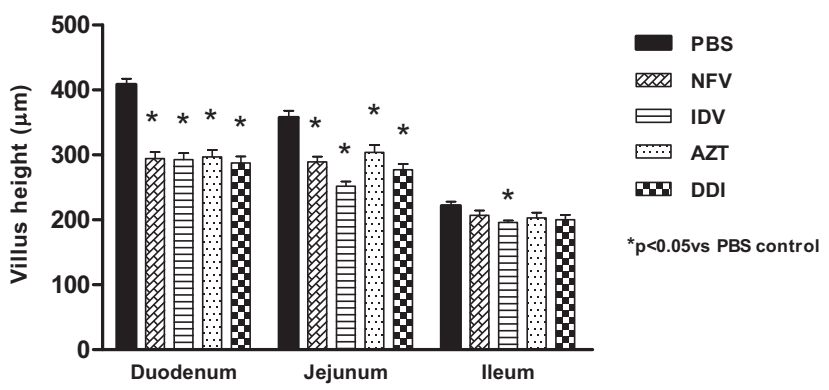

B

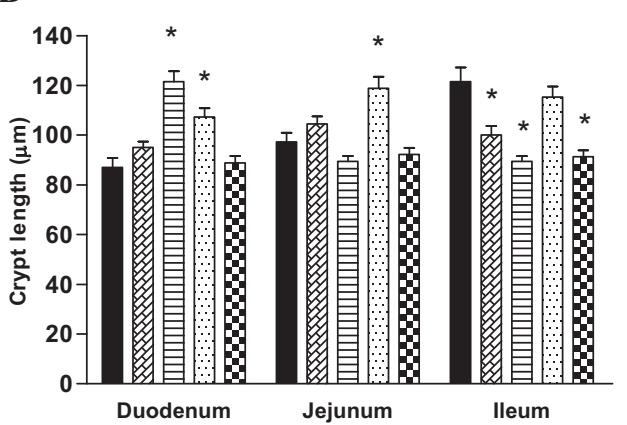

C

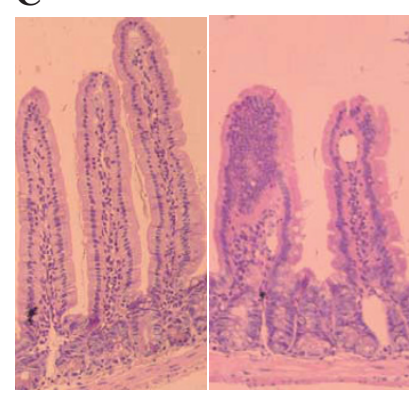

PBS

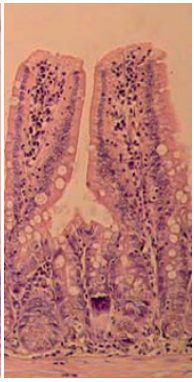

AZT

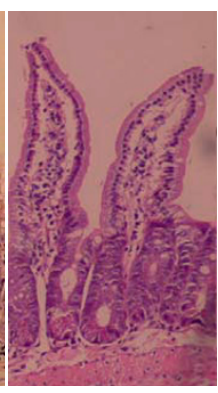

DDI

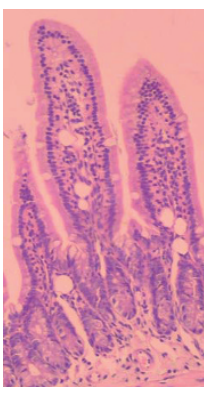

IDV

Figure 2 Villus height (A) and crypt depth (B) after 7 days of treatment with either nelfinavir (NFV, $100 \mathrm{mg} / \mathrm{kg}$ ), indinavir (IDV, 100 $\mathbf{m g} / \mathbf{k g}$ ), zidovudine (AZT, $50 \mathbf{~ m g / k g}$ ) and didanosine (DDI, $100 \mathbf{~ m g / k g}$ ) or PBS. For each animal, a total of 10 villi and 10 crypts were measured for each segment of duodenum, jejunum, and ileum with a micrometer. The results are expressed as mean \pm SEM of six mice per group. *statistical significance $(P<0.05)$ compared to the PBS control group by ANOVA, Bonferroni's multiple test. (C) Illustrative pictures of the effects of CONTROL (PBS), NFV (100 mg/kg), DDI (100 mg/kg), IDV (100 mg/kg), AZT (50 mg/kg) on the intestinal jejunal tissue, showing decreased villi length caused by all antiretrovirals and increased crypt depth caused by AZT.

ratio, when compared to the untreated control. Neither IDV, AZT nor DDI treatment altered the excretion of mannitol, lactulose or the L/M ratio (Figure 5).

\section{2) In vitro experiments \\ Cell proliferation}

The protease inhibitors, NFV and IDV, caused a significant reduction in IEC- 6 cell proliferation at both $24 \mathrm{~h}$ and $48 \mathrm{~h}$. NFV significantly inhibited cell proliferation at doses of $7,10,70$ and $100 \mathrm{ug} / \mathrm{mL}$ at $24 \mathrm{~h}$ (reduction of
$18.1 \%, 26.1 \%, 48.1 \%$ and $39.1 \%$, respectively; $\mathrm{p}<0.05$; Figure $6 \mathrm{~A}$ ) and at $48 \mathrm{~h}$ (reduction of $29.5 \%, 49 \%, 46 \%$, $48.2 \%$, respectively; $\mathrm{p}<0.05$; Figure $6 \mathrm{~A}$ ). IDV at doses of $50 \mathrm{ug} / \mathrm{mL}$ and $100 \mathrm{ug} / \mathrm{mL}$ significantly inhibited cell proliferation by $8.6 \%$ and $17 \%$, respectively, at $48 \mathrm{~h}$ and by $15 \%$ at the dose of $100 \mathrm{ug} / \mathrm{mL}(\mathrm{p}<0.05$; Figure $6 \mathrm{~B})$. Slight (4.7\%) but not significant inhibition of cell proliferation was seen with AZT at the dose of $100 \mathrm{ug} / \mathrm{mL}$ at $48 \mathrm{~h}$, with inhibition of $4.7 \%$, which was not statistically significant (Figure 6C; $\mathrm{P}>0.05$ ). Similarly, DDI 

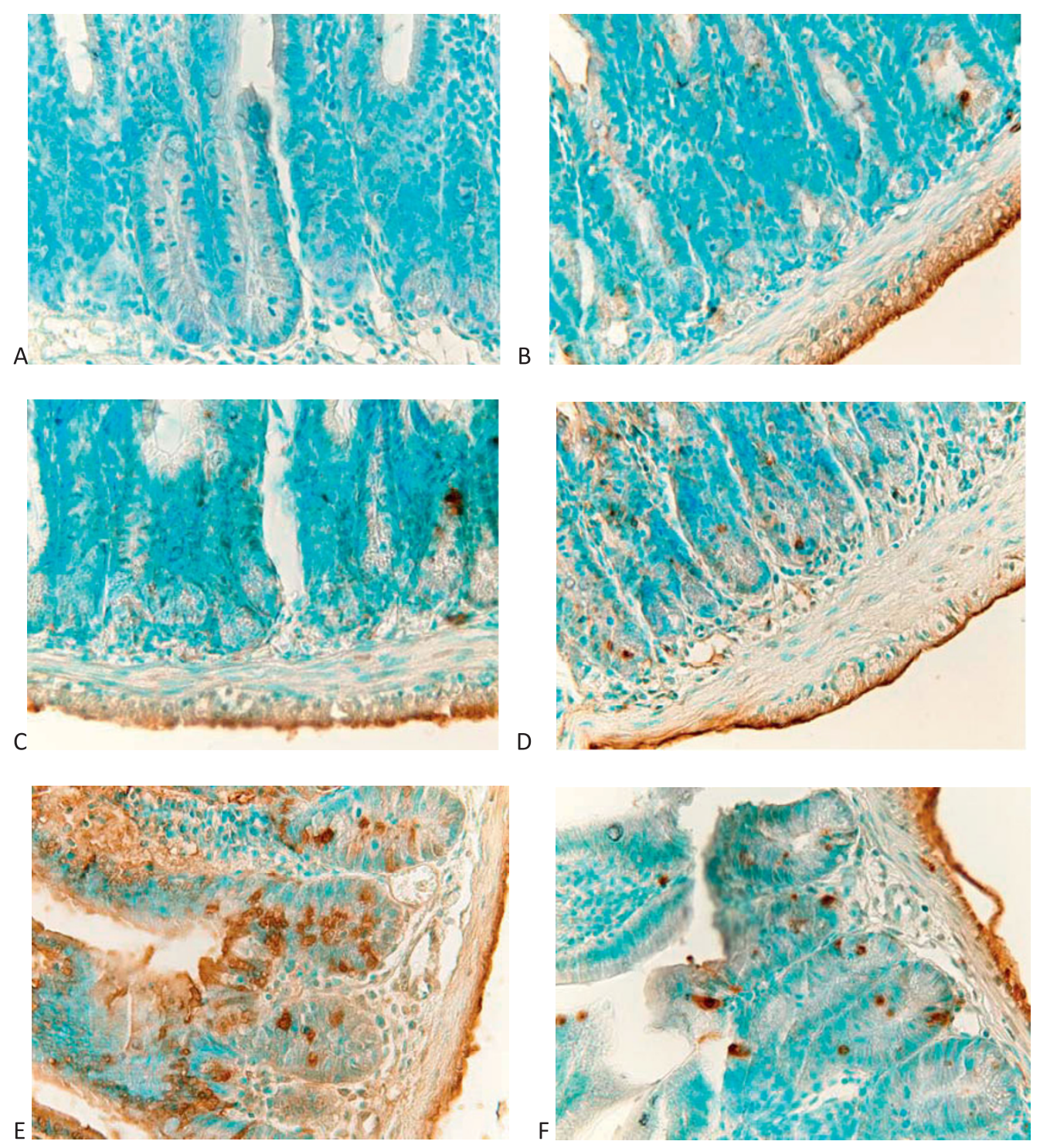

G

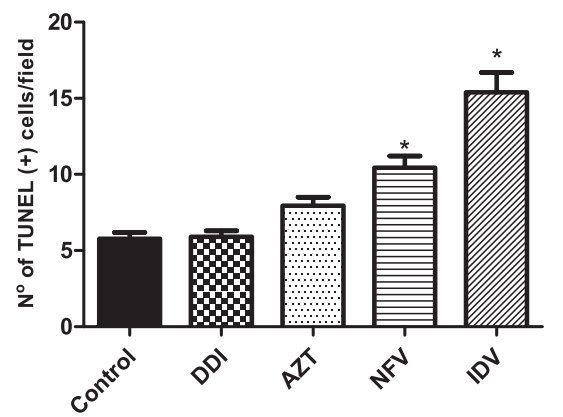

Figure 3 Illustrative pictures of the effects of antiretrovirals on cell death detected by TUNEL method (A) Negative-control (B) PBS control, (C) DDI $100 \mathrm{mg} / \mathrm{kg}$, (D) AZT $50 \mathrm{mg} / \mathrm{kg}$, (E) IDV $100 \mathrm{mg} / \mathrm{kg}$ and (F) NFV $100 \mathrm{mg} / \mathrm{kg}$ on cell death, indicated by the brown staining of the cells detected by the TUNEL method in the jejunal tissue, (G) Effects of the antiretrovirals on cell death, expressed as average of number of TUNEL-positive cells. $P<0.05$ when compared to control group (B) by one-way ANOVA and Bonferroni's test. 


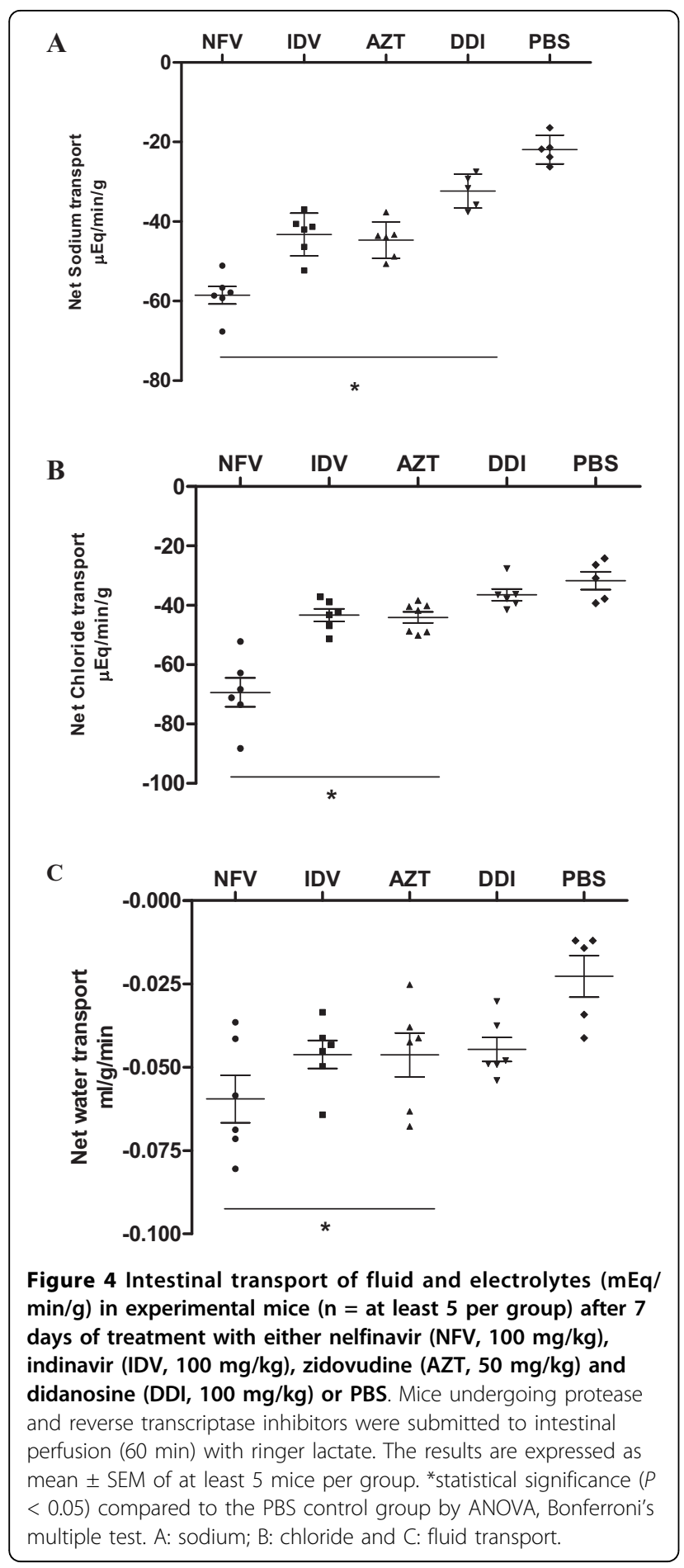

exposure did not show any significant inhibition of cell proliferation at either $24 \mathrm{~h}$ or $48 \mathrm{~h}$ (Figure 6D).

\section{Apoptosis and Necrosis}

Triplicate flow cytometry analyses demonstrated a significant increase in apoptosis in IEC-6 cells after $24 \mathrm{~h}$ incubation with $70 \mathrm{ug} / \mathrm{mL}$ of NFV (Control: $4.7 \%$ vs NFV: 22\%; P $=0.0001$; Figures 7 and 8 ). Slight, but

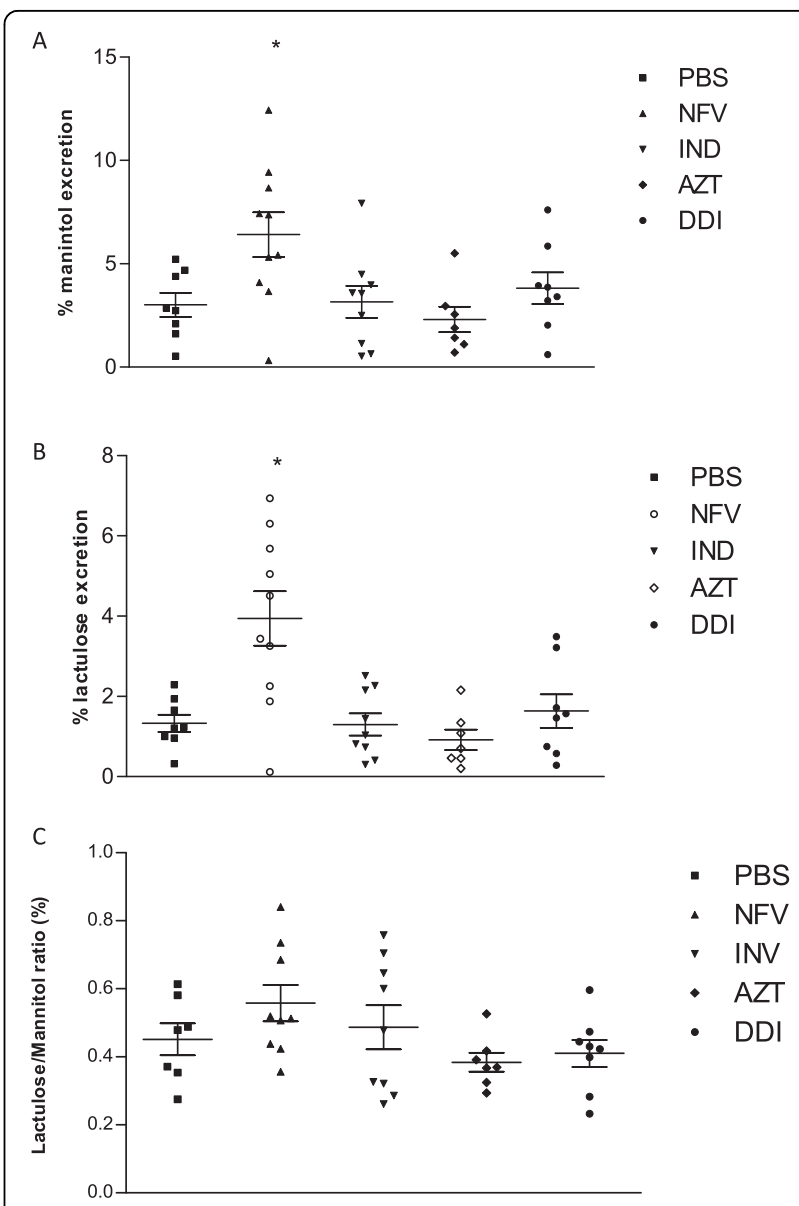

Figure 5 Lactulose and mannitol excretion (\%) in experimental mice ( $\mathrm{n}=$ at least7 per group) following 7 days of treatment with either nelfinavir (NFV, $100 \mathrm{mg} / \mathrm{kg}$ ), indinavir (IDV, $100 \mathrm{mg} /$ $\mathrm{kg}$ ), zidovudine (AZT, $50 \mathrm{mg} / \mathrm{kg}$ ) and didanosine (DDI, $100 \mathrm{mg} /$ $\mathbf{k g})$ or PBS. *statistical significance $(P<0: 05)$ compared to the PBS control group by ANOVA and Bonferroni's multiple test.

insignificant increases in IEC-6 cells apoptosis were seen after $24 \mathrm{~h}$ of exposure to $100 \mathrm{ug} / \mathrm{mL}$ IDV, $100 \mathrm{ug} / \mathrm{mL}$ AZT and $100 \mathrm{ug} / \mathrm{mL}$ DDI (Control: 4.7\% vs IDV: 8.8\%; AZT: 9.9\%; DDI: 7.4\%; P: 0.29). There was a significant increase in IEC-6 cell necrosis rates in IEC-6 after 100 $\mathrm{ug} / \mathrm{mL}$ IDV or $70 \mathrm{ug} / \mathrm{mL}$ NFV(Control: $7.7 \%$ vs $16.0 \%$; $\mathrm{P}<0.05$ and 20.54\%; $\mathrm{P}<0.05$ ), as shown in Figures 7 and 8 . There were slight increases in necrosis with at $100 \mathrm{ug} / \mathrm{mL}$ AZT and $100 \mathrm{ug} / \mathrm{mL}$ DDI that were not statistically significant. Additionally, the apoptosis rates were significantly higher with NFV than with IDV, AZT or DDI apoptosis rates $(\mathrm{P}<0.05$ by one-way ANOVA test).

\section{Discussion}

Gastrointestinal side effects of HAART are usually well tolerated and do not contribute to significant treatment discontinuation. However, diarrhea of moderate to 
A

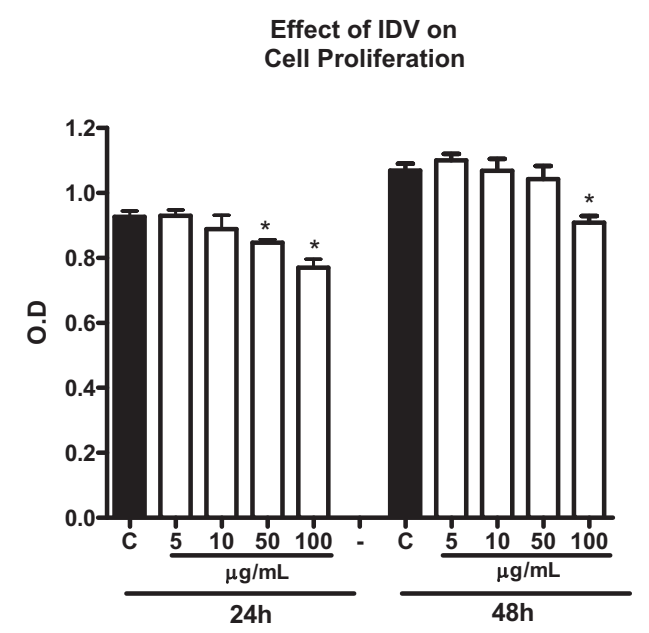

B

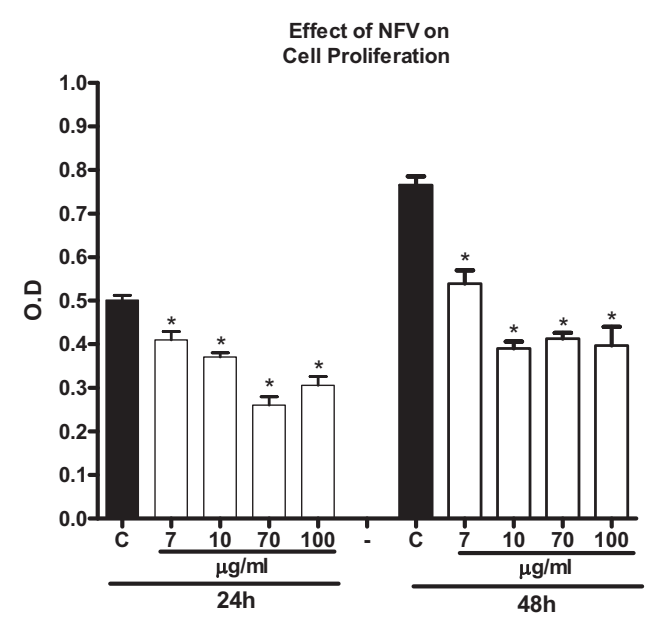

C

Effect of AZT

on Cell Proliferation

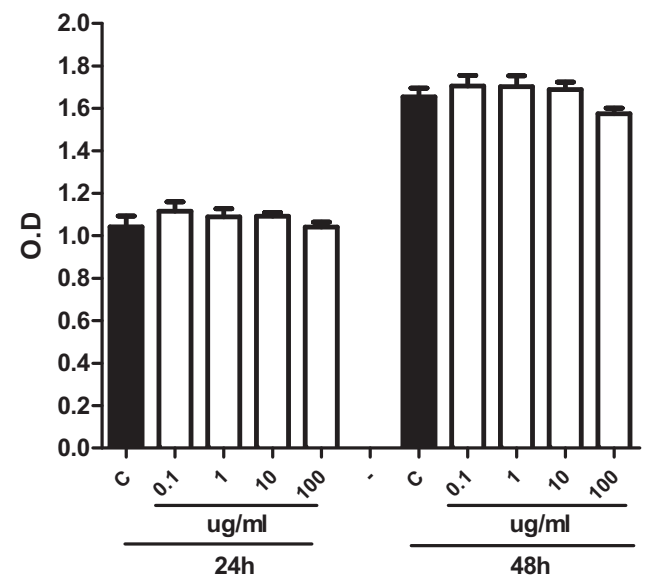

D

Effect of DDI on Cell Proliferation

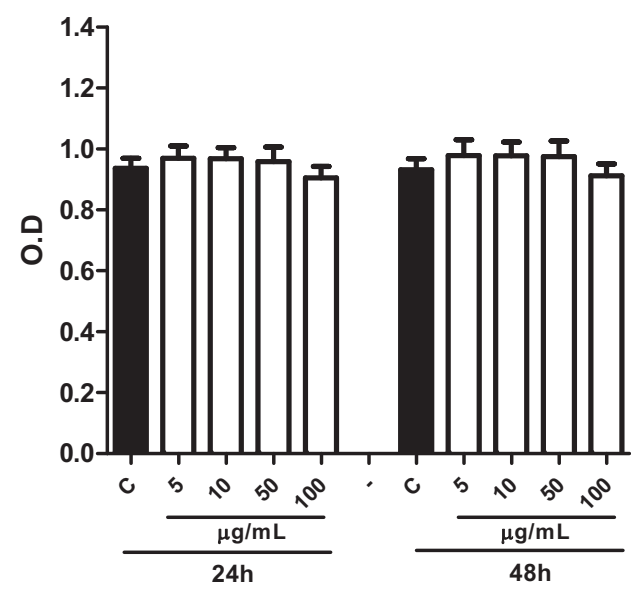

Figure 6 Effect of four different concentrations of nelfinavir (A), indinavir (B), zidovudine (C) and didanosine (D) on intestinal cell proliferation after $24 \mathrm{~h}$ and $48 \mathrm{~h}$ of exposure by detected absorbance using an ELISA microplate reader at $420 \mathrm{~nm}$ in 96 well plates seeded with IEC- 6 cells. After an exposure time of $24 \mathrm{~h}$ and $48 \mathrm{~h}$, with the antiretroviral drugs, $10 \mathrm{uL}$ of the tetrazolium salt was added to each well, and absorbance was measured after $4 \mathrm{~h}$ of incubation. ${ }^{*} \mathrm{P}<0.05$ when compared to control group (C) incubated in standard DMEM media using one-way ANOVA and Bonferroni's test.

severe intensity can occur in patients receiving multidrug therapy [21-23]. The mechanisms underlying antiretroviral-induced diarrhea are unclear. The intestinal epithelium acts as a highly selective barrier, preventing the passage of toxic molecules and luminal bacterial translocation [24]. The normal barrier function is maintained by steady enterocyte turnover finely regulated by cell proliferation, migration, and apoptosis. Cell-to-cell contacts within the intestinal epithelium structured by a scaffold of tight and adherens junctions, located apically, are further responsible for sealing the intestinal barrier
[25-27]. The results of this study suggest that selected antiretroviral drugs influence small intestinal absorptive and secretory functions.

We have assessed intestinal mucosal morphology, permeability changes, and electrolyte secretion following antiretroviral treatment in mice. All antiretroviral agents tested caused significant blunting of the absorptive villi, especially in the duodenum and jejunum. Moreover, hyperplasia of the crypt cells (which are responsible for the secretory function of the small intestine) were sometimes, noted in the duodenum (IDV, AZT) and jejunum 


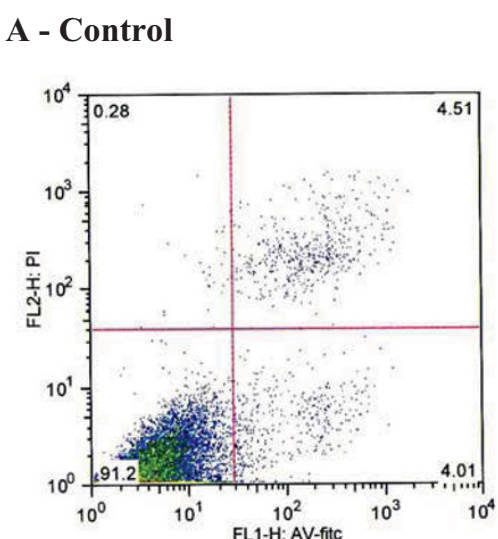

C - IDV

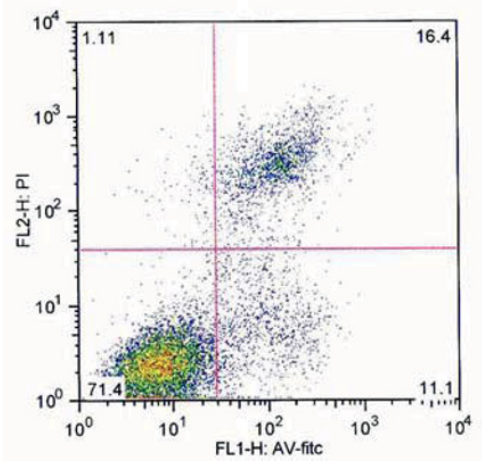

E - DDI

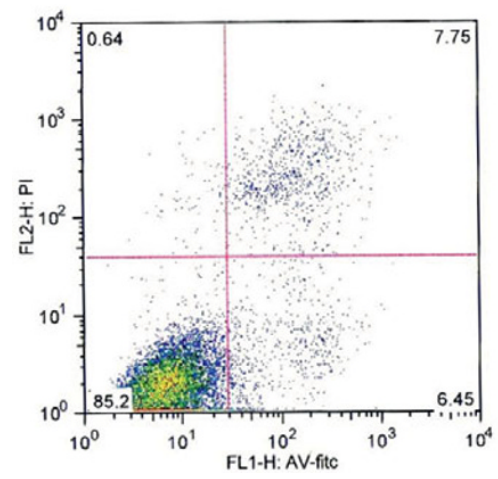

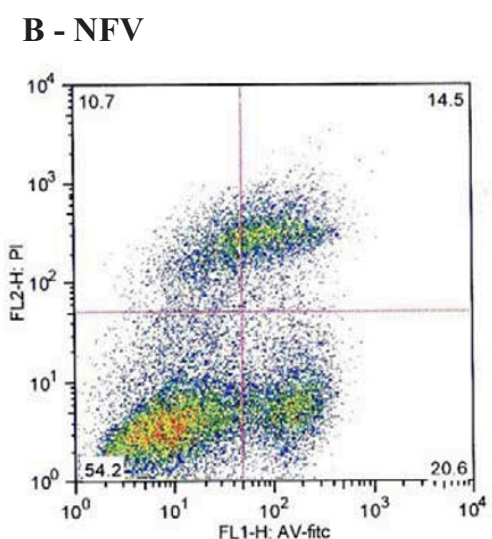

D - AZT

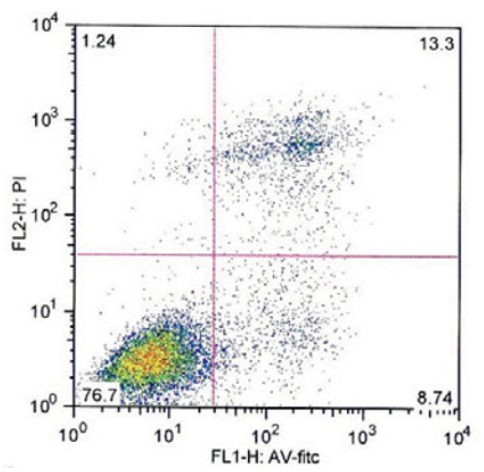
and didanosine (E) on intestinal epithelial IEC-6 cell apoptosis and necrosis after $24 \mathrm{~h}$ of exposure. Cells were stained with FITCconjugated annexin $\mathrm{V}$ and propidium iodide and analyzed by flow cytometry. Results are shown as density plots with propidium iodide vs. annexin V-FITC. Viable cells have low annexin-V-FITC and low propidium iodide staining (lower-left quadrant), apoptotic cells have high annexin V-FITC and low propidium iodide staining (lower-right quadrant), and necrotic cells have high propidium iodide and annexin V-FITC staining (upper-right quadrant).

(IDV). While HIV, per se, and concomitant enteric infections may cause mucosal atrophy $[28,29]$, our findings suggest that antiretroviral drugs may also contribute to or aggravate any enteropathy secondary to infectious causes. Mannitol and lactulose assays have been very useful to assess overall intestinal absorptive area (mannitol) and impaired epithelial barrier function (lactulose), since both sugars are passively absorbed and excreted unchanged into the urine [19,30]. Interestingly, NFV was the only drug tested that caused significant increases in both lactulose and mannitol excretion rates, thus not affecting the lactulose:mannitol ratio. We 


\section{Effect of Antiretrovirals on Cell Death at $24 \mathrm{~h}$}

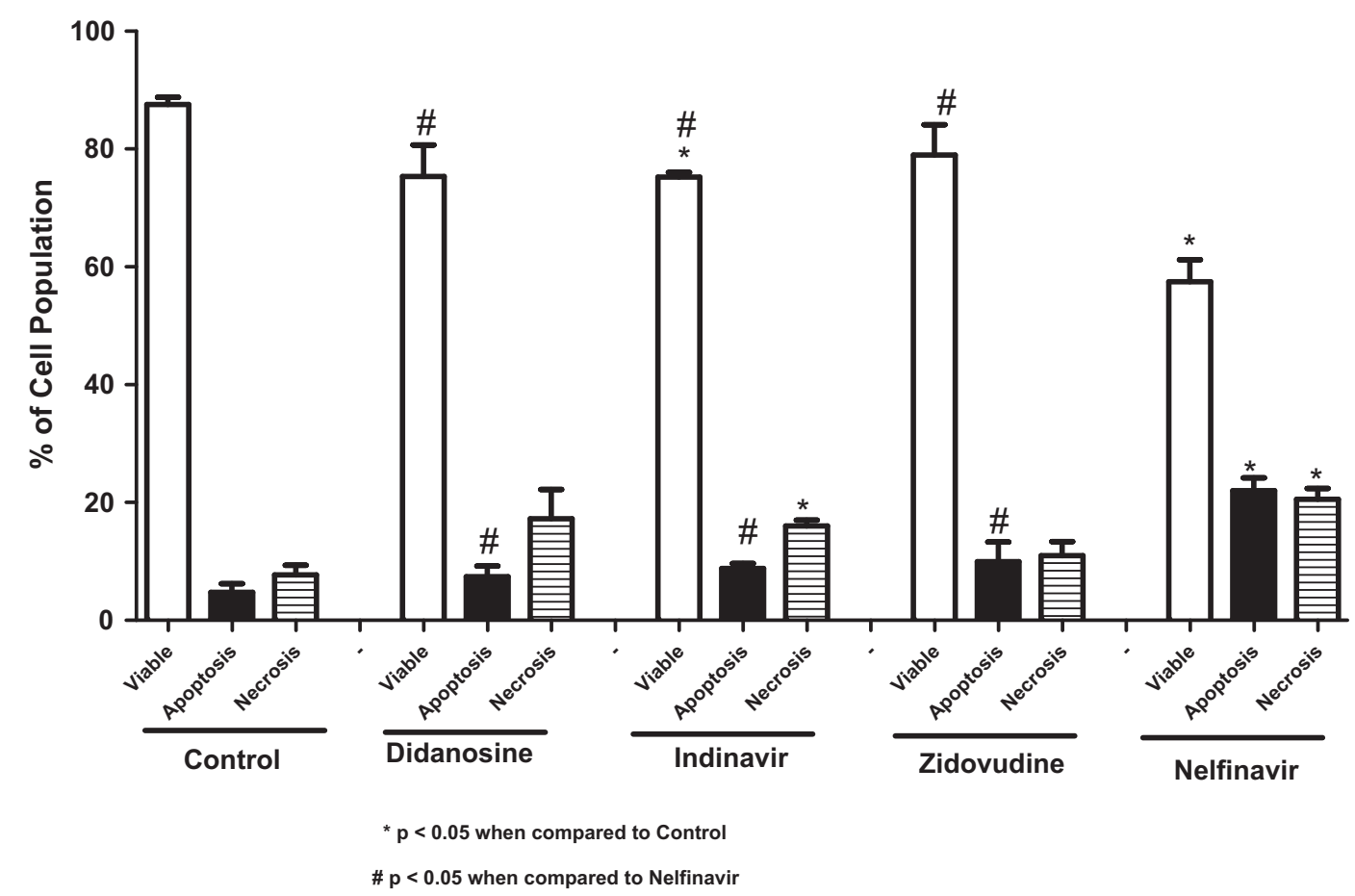

Figure 8 Percentage of cell apoptosis, necrosis, and viable cells of the untreated control group, of $70 \mathrm{ug} / \mathrm{mL}$ of NFV, $100 \mathrm{ug} / \mathrm{mL}$ of IDV, AZT and DDI on intestinal epithelial IEC- $\mathbf{6}$ cell apoptosis and necrosis after $\mathbf{2 4} \mathbf{h}$ of exposure. ${ }^{*} P<0.05$ when compared to control group $(C)$ incubated in standard DMEM media and \# $P<0.05$ when compared to the nelfinavir group by one-way ANOVA and Bonferroni's test.

speculate that NFV might have induced compensatory changes in villus area following intestinal epithelial injury. The other drugs tested did not show any significant change in lactulose excretion suggesting that epithelial tight junctions are not severely compromised by these other antiretroviral drugs. Bode et al has also described reductions in transepithelial electrical resistance (TEER) in HT-29/B6 intestinal cell monolayers, following exposure to NFV [7]. The effects of antiretroviral drugs on enterocyte tight junctions at the molecular level, however, remain to be explored. Interestingly, only AZT induced crypt hyperplasia in both the duodenum and jejunum compared with the other antiretroviral drugs (except IDV which only caused crypt hyperplasia in the duodenum). Proximal intestinal area reductions due to villus blunting and longer crypts cannot be excluded. In contrast, net sodium, chloride and water secretion are all significantly increased in animals treated with all drugs, except DDI, indicating that effects on electrolyte and water channels and thus, may help explain the development of diarrhea. It has been previously reported that NFV recruits a slowly inactivating basolateral $\mathrm{Ca}^{2+}$ pathway, potentiating muscarinic $\mathrm{Cl}^{-}$ secretion, which may lead to secretory diarrhea.
Interestingly, DDI did not cause an increase in $\mathrm{Cl}$ - or water transport, indicating a potentially different mechanism of action.

In addition to the side effects of PI-induced-diarrhea, HIV enteropathy and intestinal infections have also been shown to cause intestinal villus blunting and atrophy, leading to malabsorption [28,31]. We report in this study significant decreases in cell proliferation and increase in apoptotic and necrotic cell death in vitro, caused by NFV. Cell proliferation and death are crucial for the dynamic intestinal cell turnover process under normal physiologic conditions, but these responses become especially important during epithelial restitution following injury from various causes. Recently, it has been reported that NFV induces anchorage-independent growth and a G1 cell cycle arrest in melanoma cells by decreased activity of CDK2, a master kinase that regulates G1-S progression [32]. We postulate that DDI does not affect the cell cycle as does NFV, which would explain the lack of effects on cell proliferation in vitro. Previous studies have shown that PI's cause significant increase in apoptosis rates [7]. Recently, it has been shown that PI's activate the unfolded protein response (UPR), the ER specific stress response, disrupting the 
intestinal barrier integrity, and that reduction in $\mathrm{CHOP}$ expression, which is a UPR-induced transcription factor that mediates apoptosis, significantly reduced apoptosis both in vitro and in vivo [33]. These findings further help elucidate the different mechanisms by which HIV PI's can induce cell death in different cell lines. Indeed, our study showed a similar increase in cell apoptosis in groups treated with NFV both in vivo and in vitro. In addition, we also report a significant increase in necrosis rates caused by IDV and NFV, which had not been previously reported [7].

Our in vitro and in vivo models do not take into account other host and environmental variables including HIV infection itself or opportunistic intestinal pathogens that can certainly contribute to impaired intestinal function and responses to antiretroviral agents. HIV associated diarrhea may be partly related to muscarinic induced-chloride secretion [10]. Mucosal HIV replication might induce a pro-inflammatory and Th1mediated cytokine over-expression [34], which could additionally disrupt the intestinal barrier with increased secretion with electrolyte and water loss. Depletion of lymphocytes in the lamina propria by HIV could disrupt the immune system and increase susceptibility to opportunistic infections $[29,35]$. Drug absorption may be further compromised by opportunistic enteric infections like Cryptosporidium spp. and Micromonospora spp., the former has been found in HIV-immunocompromised patients in Brazilian settings, with and without diarrhea $[11,36,37]$. Thus, a wide range of secretory intestinal transport disruption may occur in vivo due to direct antiretroviral therapy and both systemic and intestinal infections.

\section{Conclusion}

In conclusion, this study focused on understanding the effects of protease inhibitors and reverse transcription antiretroviral drugs on the intestinal epithelium. Gaining insight into how antiretroviral agents cause diarrhea is essential in developing interventions that could potentially reduce these side effects, avoid therapy discontinuation and increase efficacy of the antiretroviral drugs. We have found that both PI's, NFV and IDV, decreased proliferation and increased necrosis in vitro and that only NFV increased apoptosis in vitro, in contrast to the reverse transcriptase inhibitors which did not have such an effect. Additionally, both PI's and reverse transcriptase inhibitors altered intestinal morphology in vivo, reducing villous height in the duodenum and jejunum and induced sodium secretion. Furthermore, NFV and IDV induced cell apoptosis in vivo and chloride and water secretion. NFV was the only drug tested that caused significant changes in intestinal permeability. Further studies are needed to elucidate molecular mechanisms involved in HIV PI-induced epithelial damage, including cell cycle studies, WNT-signaling and R-spondin-1, specific cell death pathways as well as studies to examine whether cell migration and cellular cytoskeletal F-actin are affected and contribute to disrupting the intestinal barrier. Additionally, these mechanisms might be modulated by important guttrophic nutrients, such as glutamine, alanyl-glutamine, arginine and zinc [38], which could reduce intestinal damage, increase drug absorption and decrease undesirable side effects, such as diarrhea that can be a limiting factor for treatment adherence and efficacy.

\section{Acknowledgements}

The project described was supported by award number D43 TW006578 from the Fogarty International Center and award number U01 Al026512 from the National Institute of Allergy and Infectious Diseases and in part by two Brazilian funding agencies, CNPq and CAPES and Grant \# 55000645 from the HHMI International Infectious Disease Scholarship. The following reagents used in the in vitro experiments were obtained through the AIDS Research and Reference Reagent Program, Division of AIDS, NIAID, NIH: nelfinavir, indinavir, zidovudine and didanosine. Additionally, we would like to thank Joanne Lennigan for her assistance on flow cytometry.

\section{Author details}

${ }^{1}$ Institute of Biomedicine and Clinical Research Unit-University Hospital, Federal University of Ceará, Fortaleza, Brazil. ${ }^{2}$ Center for Global Health, Division of Infectious Diseases and International Health, University of Virginia, Charlottesville, USA. ${ }^{3}$ Department of Morphology, Federal University of Ceará, Fortaleza, Brazil. ${ }^{4}$ Department of Physiology and Pharmacology, Federal University of Ceará, Fortaleza, Brazil.

\section{Authors' contributions}

MB: Participated in the in vitro and in vivo experiments, performed data analysis and drafted the manuscript. CV: Participated in the in vivo experiments, data storage, analysis and helped drafting the manuscript. JG: Participated in the in vivo experiments and data analysis. JE: Participated in the in vitro experiments and data analysis. CA: Participated in the study design and writing the paper. RB: Participated in statistical analysis and drafting and reviewing of the manuscript. GB and BO: Participated in the in vivo experiments and critical reviewing. AL and RG: Participated in the coordination, conception, experiments design and critical reviewing and writing. All authors read and approved the final manuscript.

\section{Competing interests}

The authors declare that they have no competing interests.

Received: 11 February 2010 Accepted: 11 August 2010

Published: 11 August 2010

\section{References}

1. Moreno S, López Aldeguer J, Arribas JR, Domingo P, Iribarren JA, Ribera E, Rivero A, Pulido F, HIV 2020 Project: The future of antiretroviral therapy: challenges and needs. J Antimicrob Chemother 2010, 65(5):827-35.

2. El SY, Vivet-Boudou V, Marquet R: HIV-1 reverse transcriptase inhibitors. Appl Microbiol Biotechnol 2007, 75:723-37.

3. McKinnon JE, Mellors JW, Swindells S: Simplification strategies to reduce antiretroviral drug exposure: progress and prospects. Antivir Ther 2009, 14(1):1-12.

4. Hill A, Balkin A: Risk factors for gastrointestinal adverse events in HIV treated and untreated patients. AIDS Rev 2009, 11(1):30-8.

5. Guarino A, Bruzzese E, De MG, Buccigrossi V: Management of gastrointestinal disorders in children with HIV infection. Paediatr Drugs 2004, 6:347-62. 
6. Tramarin A, Parise N, Campostrini S, Yin DD, Postma MJ, Lyu R, Grisetti R, Capetti A, Cattelan AM, Di Toro MT, Mastroianni A, Pignattari E, Mondardini V, Calleri G, Raise E, Starace F, Palladio Study Group: Association between diarrhea and quality of life in HIV-infected patients receiving highly active antiretroviral therapy. Qual Life Res 2004 13:243-50.

7. Bode H, Lenzner L, Kraemer OH, Kroesen AJ, Bendfeldt K, Schulzke JD, Fromm M, Stoltenburg-Didinger G, Zeitz M, Ullrich R: The HIV protease inhibitors saquinavir, ritonavir, and nelfinavir induce apoptosis and decrease barrier function in human intestinal epithelial cells. Antivir Ther 2005, 10:645-55.

8. Chow WA, Jiang C, Guan M: Anti-HIV drugs for cancer therapeutics: back to the future? Lancet Oncol 2009, 10(1):61-71.

9. Gills JJ, Lopiccolo J, Tsurutani J, Shoemaker RH, Best CJ, Abu-Asab MS, Borojerdi J, Warfel NA, Gardner ER, Danish M, Hollander MC, Kawabata S, Tsokos M, Figg WD, Steeg PS, Dennis PA: Nelfinavir, a lead HIV protease inhibitor, is a broad-spectrum, anticancer agent that induces endoplasmic reticulum stress, autophagy, and apoptosis in vitro and in vivo. Clin Cancer Res 2007, 13(17):5183-94.

10. Rufo PA, Lin PW, Andrade A, Jiang L, Rameh L, Flexner C, Alper SL, Lencer WI: Diarrhea-associated HIV-1 APIs potentiate muscarinic activation of $\mathrm{Cl}$ - secretion by T84 cells via prolongation of cytosolic $\mathrm{Ca} 2$ + signaling. Am J Physiol Cell Physiol 2004, 286:C998-C1008.

11. Wuhib T, Silva TM, Newman RD, Garcia LS, Pereira ML, Chaves CS, Wahlquist SP, Bryan RT, Guerrant RL, Sousa A de Q, Queiroz TRB, Sears CL: Cryptosporidial and microsporidial infections in human immunodeficiency virus-infected patients in northeastern Brazil. J Infect Dis 1994, 170:494-97.

12. Bushen OY, Davenport JA, Lima AB, Piscitelli SC, Uzgiris AJ, Silva TM, Leite R, Kosek M, Dillingham RA, Girao A, Lima AA, Guerrant RL: Diarrhea and reduced levels of antiretroviral drugs: improvement with glutamine or alanyl-glutamine in a randomized controlled trial in northeast Brazil. Clin Infect Dis 2004, 38:1764-70.

13. Berkes J, Viswanathan VK, Savkovic SD, Hecht G: Intestinal epithelial responses to enteric pathogens: effects on the tight junction barrier, ion transport, and inflammation. Gut 2003, 52:439-51.

14. Bjerknes $\mathrm{M}$, Cheng $\mathrm{H}$ : Clonal analysis of mouse intestinal epithelial progenitors. Gastroenterology 1999, 116:7-14.

15. Potten CS: Stem cells in gastrointestinal epithelium: numbers, characteristics and death. Philos Trans R Soc Lond B Biol Sci 1998, 353:821-30.

16. Clatworthy JP, Subramanian V: Stem cells and the regulation of proliferation, differentiation and patterning in the intestinal epithelium: emerging insights from gene expression patterns, transgenic and gene ablation studies. Mech Dev 2001, 101:3-9.

17. Fuchs BC, Bode BP: Stressing Out Over Survival: Glutamine as an Apoptotic Modulator. J Surg Res 2006, 131(1):26-40.

18. Kroemer G, Galluzzi L, Vandenabeele P, Abrams J, Alnemri ES, Baehrecke EH, Blagosklonny MV, El-Deiry WS, Golstein P, Green DR, Hengartner M, Knight RA, Kumar S, Lipton SA, Malorni W, Nuñez G, Peter ME, Tschopp J, Yuan J, Piacentini M, Zhivotovsky B, Melino G, Nomenclature Committee on Cell Death 2009: Classification of cell death: recommendations of the Nomenclature Committee on Cell Death 2009. Cell Death Differ 2009, 16(1):3-11.

19. Bao Y, Silva TM, Guerrant RL, Lima AM, Fox JW: Direct analysis of mannitol, lactulose and glucose in urine samples by high-performance anionexchange chromatography with pulse amperometric detection. Clinical evaluation of intestinal permeability in human immunodeficiency virus infection. J Chromatogr B Biomed Appl 1996, 685:105-12.

20. Schedl HP, Clifton JA: Solute and water absorption by the human small intestine. Nature 1963, 199:1264-7.

21. Bardsley-Elliot A, Plosker GL: Nelfinavir: an update on its use in HIV infection. Drugs 2000, 59:581-620.

22. Lemberg DA, Palasanthiran P, Goode M, Ziegler JB: Tolerabilities of antiretrovirals in paediatric HIV infection. Drug Saf 2002, 25:973-91.

23. Jarvis B, Nelfinavir Faulds D: A review of its therapeutic efficacy in HIV infection. Drugs 1998, 56:147-67.

24. Guttman JA, Li Y, Wickham ME, Deng W, Vogl AW, Finlay BB: Attaching and effacing pathogen-induced tight junction disruption in vivo. Cell Microbiol 2006, 8:634-45.
25. Utech $M$, Bruwer $M$, Nusrat A: Tight junctions and cell-cell interactions. Methods Mol Biol 2006, 341:185-95.

26. Laukoetter MG, Bruewer M, Nusrat A: Regulation of the intestinal epithelial barrier by the apical junctional complex. Curr Opin Gastroenterol 2006, 22:85-9.

27. Gasbarrini G, Montalto M: Structure and function of tight junctions. Role in intestinal barrier. Ital I Gastroenterol Hepatol 1999, 31:481-8.

28. Ullrich R, Zeitz M, Heise W, L'age M, Hoffken G, Riecken EO: Small intestinal structure and function in patients infected with human immunodeficiency virus (HIV): evidence for HIV-induced enteropathy. Ann Intern Med 1989, 111:15-21.

29. Mehandru S, Poles MA, Tenner-Racz K, Horowitz A, Hurley A, Hogan C, Boden D, Racz P, Markowitz M: Primary HIV-1 infection is associated with preferential depletion of CD4+ T lymphocytes from effector sites in the gastrointestinal tract. J Exp Med 2004, 200:761-70.

30. Barboza Junior MS, Silva TM, Guerrant RL, Lima AA: Measurement of intestinal permeability using mannitol and lactulose in children with diarrheal diseases. Braz J Med Biol Res 1999, 32:1499-504.

31. Gianotti N, Soria A, Lazzarin A: Antiviral activity and clinical efficacy of atazanavir in HIV-1-infected patients: a review. New Microbiol 2007, 30:79-88.

32. Jiang W, Mikochik PJ, Ra JH, Lei H, Flaherty KT, Winkler JD, Spitz FR: HIV protease inhibitor nelfinavir inhibits growth of human melanoma cells by induction of cell cycle arrest. Cancer Res 2007, 1; 67(3):1221-7.

33. Wu X, Sun L, Zha W, Studer E, Gurley E, Chen L, Wang X, Hylemon PB, Pandak WM Jr, Sanyal AJ, Zhang L, Wang G, Chen J, Wang JY, Zhou H: HIV protease inhibitors induce endoplasmic reticulum stress and disrupt barrier integrity in intestinal epithelial cells. Gastroenterology 2010, 138(1):197-209.

34. McGowan I, Elliott J, Fuerst M, Taing P, Boscardin J, Poles M, Anton P. Increased HIV-1 mucosal replication is associated with generalized mucosal cytokine activation. J Acquir Immune Defic Syndr 2004, 37:1228-36.

35. Ullrich R, Zeitz M, Riecken EO: Enteric immunologic abnormalities in human immunodeficiency virus infection. Semin Liver Dis 1992, 12:167-74.

36. Nannini EC, Okhuysen PC: HIV1 and the gut in the era of highly active antiretroviral therapy. Curr Gastroenterol Rep 2002, 4:392-8.

37. Lima AA, Silva TM, Gifoni AM, Barrett L, McAuliffe IT, Bao Y, Fox JW, Fedorko DP, Guerrant RL: Mucosal injury and disruption of intestinal barrier function in HIV-infected individuals with and without diarrhea and cryptosporidiosis in northeast Brazil. Am J Gastroenterol 1997, 92:1861-6.

38. Carneiro-Filho BA, Bushen OY, Brito GA, Lima AA, Guerrant RL: Glutamine analogues as adjunctive therapy for infectious diarrhea. Curr Infect Dis Rep 2003, 5:114-9.

\section{Pre-publication history}

The pre-publication history for this paper can be accessed here: http://www.biomedcentral.com/1471-230X/10/90/prepub

\section{doi:10.1186/1471-230X-10-90}

Cite this article as: Braga Neto et al: Evaluation of HIV protease and nucleoside reverse transcriptase inhibitors on proliferation, necrosis, apoptosis in intestinal epithelial cells and electrolyte and water transport and epithelial barrier function in mice. BMC Gastroenterology 2010 10:90

\section{Submit your next manuscript to BioMed Central and take full advantage of:}

- Convenient online submission

- Thorough peer review

- No space constraints or color figure charges

- Immediate publication on acceptance

- Inclusion in PubMed, CAS, Scopus and Google Scholar

- Research which is freely available for redistribution 